\title{
COVID-19, TENSIONES ENTRE CHINA Y ESTADOS UNIDOS, Y CRISIS DEL MULTILATERALISMO: REPERCUSIONES PARA AL
}

\author{
COVID-19, UNITED STATES-CHINA TENSIONS, AND THE \\ CRISIS OF MULTILATERALISM: REPERCUSSIONS FOR \\ LATIN AMERICA
}

\begin{abstract}
COVID-19, TENSIONS ENTRE LA CHINE ET LES ÉTATS-UNIS ET CRISE DU MULTI-LATÉRALISME: RÉPERCUSSIONS POUR L'AMÉRIQUE LATINE
\end{abstract}

\author{
RAÚl Bernal-Meza \\ Universidad Arturo Prat de Chile \\ rbernal@fch.unicen.edu.ar
}

RESUMEN: El artículo analiza dos procesos internacionales en curso, la rivalidad sino-estadounidense y la pandemia de Covid-19. La coincidencia de ambos ha profundizado el deterioro del multilateralismo. Para América Latina, la confluencia de estas situaciones aumenta su vulnerabilidad, exponiéndola a un escenario internacional de creciente incertidumbre, evidenciando sus escasos márgenes de maniobra. El texto aporta elementos de análisis para la comprensión de estas dinámicas globales, a partir de una reflexión teórica sobre el conflicto entre potencias y sus consecuencias para su política exterior y el futuro del multilateralismo. Así también se aborda el impacto de la Covid-19 y las tensiones en el orden internacional liberal, desde las perspectivas teóricas de la cooperación: la interdependencia compleja y el institucionalismo liberal, para entender cómo la discordia se impone a la colaboración. Todas estas tendencias afectan negativamente una América Latina que descarta la acción colectiva, tanto en sus relaciones con Estados Unidos como con China.

Palabras clave: Covid-19; orden internacional; Estados Unidos; China; América Latina.

Aвstract: The article analyzes two ongoing international processes, the rivalry between China and the United States and the Covid-19 pandemic. The concurrence of the two has led to further deterioration of multilateralism. For 
Latin America, the confluence of these situations increase its vulnerability, exposing it to an international scenario of growing uncertainty, demonstrating its limited margin for maneuver. The text presents an analysis to help understand these global dynamics, based on a theoretical reflection about the conflict between powers and its consequences for foreign policy and the future of multilateralism. It also addresses the impact of Covid-19 and of tensions in the liberal international order, from the theoretical perspectives of cooperation: complex interdependence and liberal institutionalism, in order to understand how discord wins over collaboration. All these trends have a negative impact on a Latin America that rejects collective action, in its relations with both the United States and China.

Keywords: Covid-19; international order; United States; China; Latin America.

\section{Traducción de Fionn Petch, CM IDIomas}

RÉsumé: L'article analyse deux processus internationaux en cours, la rivalité sino-américaine et la pandémie du Covid-19. Leur coïncidence a approfondi l'érosion du multilatéralisme. Pour l'Amérique latine, la confluence de ces deux états de fait accroît sa vulnérabilité car elle l'expose à un contexte international affecté par une incertitude croissante, en mettant en évidence ses marges de manoeuvre serrées. Le texte apporte des éléments d'analyse pour la compréhension de ces dynamiques mondiales, à partir d'une réflexion théorique sur le conflit entre les puissances et ses conséquences pour leur politique extérieure et l'avenir du multi-latéralisme. Les effets de la Covid-19 sont également abordés, ainsi que les tensions de l'ordre international libéral, á partir des perspectives théoriques de la coopération: l'inter-dépendance complexe et l'institutionnalisme libéral, afin de comprendre comment la discorde s'impose par-dessus la collaboration. Toutes ces tendences ont un effet négatif sur une Amérique latine qui rejette l'action collective, dans ses relations aussi bien avec les États-Unis qu'avec la Chine.

Mots-clefs : Covid-19 ; ordre international ; États-Unis ; Chine ;

Amérique latine

\section{Traducción de Rafael Segovia, CM Idiomas}

Fecha de recepción: septiembre de 2020

Fecha de aceptación: febrero de 2021 


\section{INTRODUCGIÓN}

\section{A} sistimos a una creciente rivalidad entre Estados Unidos y China, acentuada con la crisis provocada por la Covid-19. Es una lucha por la hegemonía ${ }^{1}$ regional y global, aunque no en todas las regiones del mundo se trata de una rivalidad militar y de seguridad, sino de una competencia intracapitalista por esferas de influencia económica. El crecimiento económico, tecnológico y militar de China genera crecientes tensiones.

Además, a inicios de 2020, desde China se extendió la pandemia de Covid-19, que marcará la historia del siglo xxI, afectando el desarrollo de la civilización humana, como lo hicieron otras pandemias en el pasado, por ejemplo, la gripe española, la gripe de Hong-Kong y el viH-sida. El coronavirus es un fenómeno global, de alcance comparable o más amplio que las guerras mundiales. ${ }^{2}$ Es posible que sus efectos marquen el fin del orden dirigido por Occidente y la transición a uno multipolar, en el que potencias no occidentales -China,

${ }^{1}$ Interpretamos la hegemonía según la definición de Lorenzo Fusaro, quien sigue la argumentación de Gramsci aplicada a las relaciones internacionales: "Las relaciones internacionales en el mundo capitalista 'moderno' se conceptualizan dialécticamente y el resultado es su caracterización por la rivalidad entre diferentes Estados. [...]. [La hegemonía] se basa en el poder económico y militar de un Estado en relación con otros (el cual puede cambiar con el tiempo) y describe el grado de autonomía de un Estado y, por tanto, su habilidad de influir sobre la conducta de otros Estados de distintas maneras". Traducción propia; Lorenzo Fusaro, "Gramsci's Concept of Hegemony at the National and International Level", presentación durante la conferencia anual de la International Initiative for Promoting Political Economy (IIPPE), Rétino, septiembre de 2010, https://www.researchgate.net/publication/315643553_Gramsci's_ concept_of_hegemony_at_the_national_and_international_level (consulta del 14 de enero de 2021).

${ }^{2}$ Gian Luca Gardini, "Introducción: un marco para el análisis y la reflexión", en Gian Luca Gardini (coord.), El mundo antes y después del Covid-19, Salamanca, Instituto Europeo de Estudios Internacionales, 2020, p. 1. 
pero también otras, como India- desempeñen un papel más significativo. ${ }^{3}$ En este sentido, acelera las tensiones entre la potencia declinante y la ascendente, e impulsa la transición sistémica más importante desde el fin de la Guerra Fría.

Las transiciones de poder y la declinación y ascenso de potencias no suelen ser fenómenos pacíficos, ${ }^{4}$ pero también conllevan innovaciones en cuanto a las instituciones reguladoras, en particular las multilaterales. Ocurrió en el momento del orden multipolar posterior a la Primera Guerra Mundial, respecto a las relaciones entre los Estados, con la creación de la Sociedad de las Naciones y la Organización Internacional del Trabajo (OIT), y lo mismo hacia el fin de la Segunda Guerra Mundial, con el establecimiento de las Naciones Unidas y las instituciones financieras de Bretton Woods, bajo el liderazgo de Estados Unidos, que se convirtió en garante del llamado orden liberal internacional (OLI) y de sus instituciones durante los siguientes setenta años. ${ }^{5}$

Bajo la administración del presidente Donald Trump (2017-2021), las políticas del America First y el retorno a la gran estrategia ${ }^{6}$-basada en la doctrina de la contención a

${ }^{3}$ Jorge Heine, “¿Un mundo (y un orden mundial) al revés?”, en Gian Luca Gardini (coord.), op. cit., p. 25.

${ }^{4}$ Ver al respecto Robert Gilpin, War and Change in World Politics, Cambridge, University Press, 1981 y Paul Kennedy, The Rise and Fall of the Great Powers, Nueva York, Random House, 1987. Más recientemente, Graham Allison, Destined for War: Can America and China Escape Thucydides's Trap?, Nueva York, Houghton Mifflin Harcourt, 2017.

${ }^{5}$ Según la definición de John Ikenberry, se trata de un orden abierto y basado en reglas, que se plasma en instituciones como las Naciones Unidas y normas como el multilateralismo, los derechos humanos y el libre comercio. G. John Ikenberry, "The Future of the Liberal World Order", Foreign Affairs, vol. 90, núm. 3, 2011, pp. 56-68. Ver también Charles Powell, “¿Tiene futuro el orden liberal internacional?", Real Instituto Elcano, 29 de junio de 2017 (http://www.realinstitutoelcano.org/wps/portal/rielcano_es/contenido?WCM_GLOBAL_CONTEXT=/elcano/ elcano_es/zonas_es/ari56-2017-powell-tiene-futuro-orden-liberal-internacional (consulta del 13 de enero de 2021).

${ }^{6}$ Sobre la gran estrategia, ver Daniel Drezner, Ronald Krebs y Randall Schweller, "The End of Grand Strategy", Foreign Affairs, vol. 99, núm. 3, 
la $\mathrm{URSS}^{7}$-, destinadas a enfrentar el desafío chino a los intereses políticos y económicos estadounidenses, han profundizado la crisis del oLI y del sistema multilateral, respaldados ambos por la hegemonía estadounidense. ${ }^{8}$ La Covid-19, el mayor desafío a la seguridad de la población mundial desde 1945 , profundiza esta crisis. En consecuencia, la opinión dominante supone graves consecuencias para el oLI y el multilateralismo. ¿Qué significan estos retos para América Latina?

Las relaciones e influencias de ambas potencias no se distribuyen homogéneamente. Mientras para Estados Unidos, México y América Central son de gran importancia debido a la convergencia de agendas comerciales, migratorias y de narcotráfico, esa presencia e influencia disminuye en Sudamérica. A la inversa, la presencia de China es cada vez más importante en Sudamérica, ${ }^{10}$ pero comenzó a crecer en im-

2020, pp. 107-117; Graham Allison, "The New Spheres of Influence: Sharing the Globe with Other Great Powers", Foreign Affairs, vol. 99, núm. 2, 2020, pp. 30-40 y John L. Gaddis, On Grand Strategy, Nueva York, The Penguin Press, 2018.

${ }^{7}$ John L. Gaddis, Strategies of containment: a critical appraisal of postwar American national security policy, Nueva York, Oxford University Press, 1982; John L. Gaddis, The United States and the Origins of the Cold War, 1941-1947, Nueva York, Columbia University Press, 2001.

${ }^{8}$ G. John Ikenberry, "La crisis del orden liberal mundial", Anuario Internacional CIDOB 2018, 2018, pp. 29-36.

${ }^{9}$ G. John Ikenberry, "The Next Liberal Order The Age of Contagion Demands More Internationalism, Not Less", Foreign Affairs, vol. 99, núm 4, 2020, pp. 133-142; Alexander Cooley y Daniel H. Nexon, "How Hegemony Ends the Unraveling of American Power “, Foreign Affairs, vol. 99, núm 4., 2020, pp. 143-155; Ian Bremmer, "Coronavirus and the World Order to Come", Horizons, núm 16, 2020, pp. 14-23; Raúl Bernal-Meza, “¿Orden regulado por la anarquía?”, Clarín, 19 de abril de 2020, https:// www.clarin.com/opinion/-orden-regulado-anarquia-_0_mqSkpYYXW. html (consulta del 18 de septiembre de 2020); Raúl Bernal-Meza y Li Xing, "EE.UU versus China: ¿nueva Guerra Fría?", Clarín, 2 de agosto de 2020, https://www.clarin.com/opinion/ee-uu-versus-china-nueva-guerrafria-_0_snq8oxGdL.html (consulta del 18 de septiembre de 2020).

${ }^{10}$ Raúl Bernal-Meza y Li Xing (eds.), China-Latin America Relations in the 21st Century. The Dual Complexities of Opportunities and Challenges, Nueva York, Palgrave Macmillan, 2020. 
portancia económica en América Central desde la década pasada. ${ }^{11}$ No obstante, la presencia comercial china en México sí es un tema de preocupación para Estados Unidos, debido al impacto de la balanza comercial de México con Beijing, cuyo déficit comercial es responsable de dos tercios del déficit de todos los países de la región en su intercambio con Beijing. ${ }^{12}$

Estos aspectos tendrán incidencia en los posicionamientos regionales frente a la reconfiguración del orden liberal internacional, el multilateralismo y las opciones de relación frente a ambas potencias.

Este artículo busca aportar elementos de análisis para la comprensión de las dinámicas globales: crisis del multilateralismo, rivalidad sino-estadounidense y pandemia del coronavirus, y sus consecuencias para los países de la región. Se argumenta que la confluencia de estas situaciones aumenta la vulnerabilidad de América Latina, exponiéndola a un escenario internacional de creciente incertidumbre, evidenciando sus escasos márgenes de maniobra.

La reflexión se estructura en tres partes. En la primera se aborda el conflicto sino-estadounidense a través de tres enfoques teóricos, y de la revisión de los cambios recientes en ambas políticas exteriores. En la segunda se analiza el impacto de la pandemia y las tensiones en el oLI, desde las perspectivas de la interdependencia compleja y del institucionalismo liberal. Estas tensiones reflejan la discordia que se impone a la necesaria cooperación internacional, lo que se observa en la Organización Mundial de la Salud (oms). La tercera interroga cómo estas tensiones entre China y Estados Unidos, al

${ }^{11}$ Enrique Dussel Peters, "Las ‘nuevas relaciones triangulares' de América Latina y el Caribe: entre 'el proceso de globalización con características chinas' y tensiones con Estados Unidos”, en Wolf Grabendorff y Andrés Serbin (eds.), Los actores globales y el (re)descubrimiento de América Latina, Barcelona, Icaria Editorial/CRIES e Icaria Editorial, 2020, pp. 133-144.

12 Ver al respecto, Explorando nuevos espacios de cooperación entre América Latina y el Caribe y China, Santiago, Naciones Unidas, Cepal, 2018, LC/ TS.2018/6, pág. 40. 
fomentar la búsqueda de esferas de influencia afecta a América Latina en el contexto de la Covid-19.

\section{LA RIVALIDAD SINO-ESTADOUNIDENSE, AGUDIZADA POR LA PANDEMIA}

La rivalidad creciente entre las dos principales potencias mundiales puede analizarse a partir de diferentes perspectivas teóricas que llevan a la reaparición de la lógica de esferas de influencia. Esta tendencia ya se percibe en los cambios de política exterior observados tanto en Estados Unidos como en China.

Rivalidad sino-estadounidense: posibles enfoques teóricos-metodológicos

Tres enfoques teórico-metodológicos pueden explicar la rivalidad sino-estadounidense. El primero proviene de la teoría de la estabilidad hegemónica ${ }^{13}$ y del cambio mundial, ${ }^{14}$ que vincula la lucha entre potencias con los factores económicos. Define la situación como el desafío de una potencia ascendente a una potencia hegemónica, y parte de una perspectiva histórica sobre el ascenso y declive de las grandes potencias. ${ }^{15}$ La historia del sistema internacional es la de un permanente desafío entre potencias. El ascenso de un actor desafiante genera el cambio internacional que conduce al reemplazo del hegemón. Por ejemplo, la rivalidad y las tensiones en el mar de China meridional hacen que la importancia del poder militar recobre actua-

${ }^{13}$ Charles Kindleberger, The World in Depression, 1929-1939, Berkeley, University of California Press, 1973.

${ }^{14}$ Robert Gilpin, The Political Economy of International Relations, Cambridge, University Press, 1987.

${ }^{15}$ Paul Kennedy, op. cit. 
lidad. ${ }^{16}$ La potencia ascendente china reclama el reconocimiento de una esfera de influencia ${ }^{17}$ y desafía el oLI impuesto por Estados Unidos.

El segundo enfoque parte de una visión crítica del capitalismo y considera la rivalidad como una competencia imperialista entre dos potencias capitalistas. Estados Unidos y China están inmersos en un conflicto ${ }^{18}$ comercial que puede desembocar en una competencia económica. ${ }^{19}$ Siguiendo las interpretaciones clásicas sobre el imperialismo, ${ }^{20}$ estaríamos en presencia de un conflicto entre dos modelos en el marco de la economía política capitalista. ${ }^{21}$ China se consolida como una potencia que extiende su esfera de influencia económica hacia diferentes zonas a través de la Iniciativa de la Franja y la Ruta (Belt and Road Initiative o BRI) y desarrolla una política imperialista en América Latina ${ }^{22}$ y en África. ${ }^{23}$ Como consecuencia, la rivalidad entre Estados Unidos y China seguirá intensificándose, sin importar quién gane, porque

${ }^{16}$ Gabriela Varas, "China acusa a EE.uU. de 'crear caos' en Asia para mantener su hegemonía”, Emol, 24 de noviembre de 2020, https:/ /www. emol.com/noticias/Internacional/2020/11/24/1004711/China-Estados-Unidos-caos-Asia.html (consulta del 13 de enero de 2021).

17 Graham Allison, "The New Spheres of Influence”, op. cit.; Drezner, Krebs y Schweller, op. cit.; G. John Ikenberry, op. cit., 2020.

18 Utilizamos el concepto de "conflicto" en el marco de la economía política capitalista, pues se trata de una confrontación que se manifiesta en medidas y retaliaciones de carácter económico-comercial y tecnológico.

19 David A. Lake, "Economic Openness and Great Power Competition: Lessons for China and the United States", The Chinese Journal of International Politics, vol. 11, núm. 3, 2018, pp. 237-270.

${ }^{20}$ John Hobson, Imperialism: A Study, Nueva York, James Pott \& Company, 1902; Vladimir Lenin, Imperialism, the Highest Stage of Capitalism, Moscú, Progress Publishers, 1917.

${ }^{21}$ Li Xing, “China's Global Rise and Neoimperialism: Attitudes and Actualities", en Immanuel Ness y Zak Cope (eds.), Palgrave Encyclopedia of Imperialism $\mathcal{E}^{2}$ anti-imperialism, Londres, Palgrave Macmillan, 2016.

${ }^{22}$ Raúl Bernal-Meza y Li Xing (eds.), China-Latin America Relations in the 21st Century, op. cit.

${ }^{23}$ Li Xing y Abdulkadir Osman Farah (eds.), China-Africa Relations in an Era of Great Transformations, Surrey, Ashgate, 2013. 
es de carácter capitalista, interimperial e impulsada por la competencia de mercados. ${ }^{24} \mathrm{El}$ proyecto BRI es otro desafío al orden liderado por Estados Unidos. ${ }^{25}$ Según esta perspectiva, las esferas de influencia son parte del enfrentamiento por la distribución regional y global del trabajo. ${ }^{26}$

El tercer enfoque, realista clásico, se concentra en la dimensión política del conflicto y explica la rivalidad y las tensiones como resultado de la política internacional de Estados Unidos, que pone a China en el lugar de la ex Unión Soviética. China desafía el orden internacional y debe ser contenida mediante la continuación de una gran estrategia; comienza a ser una preocupación y Washington se prepara para una prolongada lucha por el dominio, también con Rusia y otras potencias rivales. ${ }^{27} \mathrm{El}$ conflicto ideológico se refuerza por la creciente percepción de Xi Jinping, presidente de la República Popular desde 2013, como un líder ideológicamente duro, que sigue una política exterior agresiva. ${ }^{28}$ Según Fareed Zakaria, la política exterior china es actualmente la amenaza más importante para los intereses estadounidenses y el

${ }^{24}$ Ho-Fung Hung, "The US-China Rivalry is About Capitalist Competition", Jacobin, 11 dejulio de 2020 https:/ / www.jacobinmag.com/2020/07/ us-china-competition-capitalism-rivalry (consulta del 13 de enero de 2021); Li Xing, "The Rise of China and its Impact on World Economic Stratification and Re-Stratification", Cambridge Review of International Affairs, 2020, https://doi.org/10.1080/09557571.2020.1800589

${ }^{25}$ Hugh White, "China's One Belt, One Road to Challenge US-Led Order", The Straits Times, 25 de abril de 2017, https://www.straitstimes. com/opinion/chinas-one-belt-one-road-to-challenge-us-led-order (consulta del 13 de enero de 2021).

${ }^{26}$ Li Xing, "The Rise of China and the US-Led World Order: Can Two Tigers Share the Same Mountain?", en Bart Gaens y Ville Sinkkonen (eds.), Great-Power Competition and The Rising US-China Rivalry, Helsinki, Finnish Institute of International Affairs, 2020, pp. 57-71.

${ }^{27}$ G. John Ikenberry, "The Rise of China and the Future of the West", Foreign Affairs, vol. 87, núm. 1, 2008, pp. 23-37; G. John Ikenberry, "The Next Liberal Order", op. cit.

${ }^{28}$ Minxin Pei, "China's Coming Upheaval Competition, the Coronavirus, and the Weakness of Xi Jinping", Foreign Affairs, vol. 99, núm. 3, 2020, pp. 82-95. 
orden internacional basado en reglas que Estados Unidos creó después de $1945 .^{29}$ Tal percepción también fortalece la importancia de las esferas de influencia. Ellas se vuelven rígidas y los Estados se ven impedidos de realinearse. ${ }^{30}$ Este podría ser el caso para los países latinoamericanos.

Según estos enfoques, problemas comerciales, tecnológicos, políticos, diplomáticos y de seguridad, además del origen de la Covid-19 y de temas sobre asuntos que China considera que atañen a su soberanía pero que para Estados Unidos forman parte de su agenda liberal de política exterior, configuran un panorama en el cual las dos potencias evolucionan hacia lo que se ha denominado como "una nueva guerra fría", ${ }^{31}$ que ha tenido consecuencias en la definición de sus políticas exteriores.

Cambios en la política exterior de ambas potencias: la inclinación al conflicto

Para comprender los factores políticos que hacen posible que ambas potencias se refieran a una nueva guerra fría entre ellas, es necesario identificar los cambios en las políticas exteriores que han alimentado las tensiones, y preguntarnos si podemos identificar políticas hacia nuestra región, en

${ }^{29}$ Fareed Zakaria, “The New China Scare. Why America Shouldn't Panic about its Latest Challenger", Foreign Affairs, vol. 99, núm 1, 2019, pp. 52-69.

${ }^{30}$ Kenneth Waltz, Theory of International Politics, Nueva York, McGraw Hill, 1979, p. 163.

${ }^{31}$ Henry Kissinger, "Kissinger Warns U.S. and China Must Set Limits to Avoid a Blowup", Bloomberg News, 7 de octubre de 2020, https:/ /www.bloomberg.com/news/articles/2020-10-07/kissinger-warns-u-s-and-china-must-set-limits-to-avoid-a-blowup (consulta del 13 de enero de 2021). También, Kevin Rudd, "The Coming Post-COVID Anarchy The Pandemic Bodes Ill for Both American and Chinese Power -and for the Global Order", Foreign Affairs, 6 de mayo de 2020, https://www.foreignaffairs.com/articles/uni ted-states/2020-05-06/coming-post-covid-anarchy (consulta del 18 de septiembre de 2020). 
relación con la pandemia, la ayuda sanitaria y económica. Observamos, en ambos casos, una tendencia a privilegiar posturas conflictivas, lo cual remite a la teoría realista. Hans Morgenthau argumentó que el poder político consiste en una relación entre los que lo ejercen y aquéllos sobre los cuales se ejerce, y que es posible gracias a la primacía de factores materiales: capacidad militar y potencial económico. Explicó el comportamiento del Estado sobre la base del interés nacional -definido en términos de poder- como el objetivo normal que persiguen los gobiernos cuando les era posible hacerlo. ${ }^{32}$

En la política exterior estadounidense reciente se han producido dos cambios que conducen a un mismo resultado: la confrontación con China. El primero es que los responsables de adoptar decisiones rechazan la existencia de las "esferas de influencia", pensamiento que surgió al final de la Guerra Fría y el inicio del periodo unipolar de hegemonía estadounidense. ${ }^{33}$ Méndez y Turzi recuerdan que uno de los cuatro objetivos del papel de Estados Unidos en el mundo fue evitar el surgimiento de esferas de influencia. ${ }^{34} \mathrm{El}$ segundo cambio es la decisión de retornar a la gran estrategia -la competencia entre grandes potencias- que recuperara el sentido del viejo conflicto Este-Oeste, ahora frente a China. ${ }^{35}$ 1948.

${ }^{32}$ Hans J. Morgenthau, Politics Among Nations, Nueva York, Knopf,

${ }^{33}$ Graham Allison, "The New Spheres of Influence", op. cit.; Daniel Drezner, Ronald R. Krebs y Randall Schweller, op. cit.

34 Álvaro Méndez y Mariano Turzi, The Political Economy of China-Latin America Relations: The AIIB Membership, Cham, Springer Nature, 2020.

35 Drezner, Krebs y Schweller, op. cit.; Graham Allison, "The New Spheres of Influence", op. cit:; John Kemp, "United States and China Enter a New Cold War: Kemp", Reuters, 22 de julio de 2020, https:/ / www.reuters. com/article/us-global-politics-kemp-column/united-states-and-china-en ter-a-new-cold-war-kemp-idUSKCN24N1MT ; Matthew Fisher, "Commen tary: A New 'Cold War' is Developing between China and the U.S.", Global News, 10 de agosto del 2020, https://globalnews.ca/news/7256840/chinaus-cold-war/ 
Por su parte, China pasó de una política centrada en las ganancias económicas a la predisposición a luchar por el poder. Como he argumentado anteriormente, la estrategia de mantener un bajo perfil (strategy of keeping a low profile o KLP), centrado en las ganancias económicas y no en la disputa por el poder, se consolidó tras la masacre de Tiān'ānmén. ${ }^{36}$ Esta política sería rebatida y abandonada por Xi Jinping, como lo demuestra su discurso durante la conferencia de asuntos exteriores del Partido Comunista de China (PCC), llevada a cabo el 24 de octubre de 2013, cuando presentó la estrategia de Fènfā yǒu wéi, esforzarse por el logro o "estar dispuesto a batirse por los objetivos propuestos" (pensamiento SFA o strategy of striving for achievement). Para Richard Haass, el comportamiento reciente de China es representativo de una nueva era en su política exterior. ${ }^{37}$ Hace veinte años John Mearsheimer advertía que "tal como los Estados Unidos dejó claro a las potencias distantes que no podían entrometerse en el hemisferio occidental, China dejará claro que la interferencia americana en Asia es inaceptable". ${ }^{38}$ De hecho, Estados Unidos comienza a ser desafiado por "los lobos guerreros" de China. Un artículo publicado en el Global Times lo señala así:

Los diplomáticos chinos fueron alguna vez conocidos por su perfil bajo y conservador, en China y en los asuntos mundiales [...]. Pero el mundo y los diplomáticos chinos han cambiado.

${ }^{36}$ Raúl Bernal-Meza, "Dos aportes teóricos latinoamericanos de relaciones internacionales y su utilización por el pensamiento chino contemporáneo: los casos de Prebisch y Escudé”, Estudios Sociales, núm. 64, 2018, pp. 75-87.

${ }^{37}$ Richard Haass, "Hasta el límite con China", Project Syndicate, 13 de agosto de 2020, https://www.project-syndicate.org/commentary/coldwar-or-managed-competition-with-china-by-richard-haass-1-2020-08/ spanish (consulta del 18 de septiembre de 2020).

38 "Just as the United States made it clear to distant great powers that they were not allowed to meddle in the Western Hemisphere, China will make it clear that American interference in Asia is unacceptable", John Mearsheimer, The Tragedy of Great Power Politics, Nueva York, Norton \& Company, 2001, p. 102. 
A ojos de algunos occidentales, están usando un estilo diplomático de 'lobo guerrero' [...]. Los días en que China podía ser sometida han quedado atrás. Su estatus ascendente requiere la salvaguardia de sus intereses nacionales de manera inequívoca.

Así expresa una interpretación realista del poder y de la hegemonía estadounidense en la conducción política china. ${ }^{39}$

La pandemia empeora el escenario. La agenda sanitaria pasa a ser parte de los temas de confrontación. Estados Unidos utiliza la Covid-19 para atacar a China. ${ }^{40} \mathrm{Su}$ retórica de confrontación se inscribe en la política de America First, que condujo a una respuesta nacionalista que considera la pandemia como una amenaza a la soberanía de los Estados Unidos y la seguridad de sus ciudadanos. La idea de que la pandemia fuera un problema de salud pública mundial y no sólo de Estados Unidos quedó fuera de su política internacional. Así, no había política sanitaria multilateral posible.

Además, la comunicación y el intercambio cultural -bases de la diplomacia pública y símbolos del soft power- han servido a las dos potencias para la práctica discursiva que alimenta el hard power, debilitando uno de los importantes instrumentos de la diplomacia contemporánea. El gobierno de Donald Trump usó la denuncia contra China para desprestigiar a Beijing. Por las consecuencias sanitarias y económicas de la pandemia, el poder blando chino ha corrido el riesgo de ser destruido. ${ }^{41}$

39 "West Feels Challenged by China's New 'Wolf Warrior' Diplomacy", Global Times, 16 de abril de 2020, https://www.globaltimes.cn/content/ 1185776.shtml, (consulta del 18 de septiembre de 2020).

${ }^{40}$ La pandemia de la Covid-19 ha permitido a Estados Unidos y algunos de sus aliados acusar a China de ser responsable de su propagación. Michael R. Pompeo, "Secretary Michael R. Pompeo With Julian Reichelt of BILD-TV”, Departamento de Estado, 13 de abril de 2020, https:/ / www. state.gov/secretary-michael-r-pompeo-with-julian-reichelt-of-bild-tv/ (consulta del 18 de septiembre de 2020).

41 "Exclusive: Internal Chinese Report Warns Beijing Faces TiananmenLike Global Backlash over Virus", Reuters, 4 de mayo de 2020, https:/ /www. reuters.com/article/us-health-coronavirus-china-sentiment-ex/ exclusive- 
La administración Trump lideró respuestas multilaterales contra China en la agenda sanitaria, pero no en otras agendas globales. El deterioro del orden internacional liberal ocasionado por su gobierno no fue fortuito. Obedeció a una visión crecientemente influyente en Estados Unidos acerca de que China y otras potencias se estarían beneficiando de forma injusta y desproporcionada de un orden cuya filosofía fundacional nunca compartieron..$^{42}$ En otros lugares del mundo -China, Rusia, India, parte de América Latina y África- el oli se percibe como un sistema concebido para perpetuar la hegemonía estadounidense y sirve a sus propios intereses nacionales. ${ }^{43}$

Para el Sur global, ${ }^{44}$ esa rivalidad debilita el multilateralismo y afecta los intereses de los países en desarrollo, incluyendo América Latina, que no tienen la capacidad de influir sobre las superpotencias, dadas las asimetrías de poder y la dependencia económica. ${ }^{45}$

DETERIORO DE LA COOPERAGIÓN INTERNAGIONAL DEBIDO A LA RIVALIDAD SINO-ESTADOUNIDENSE Y AL CONTEXTO PANDÉMICO

La pandemia pone en evidencia dos importantes aspectos de las relaciones internacionales estrechamente vinculados: la vi-

internal-chinese-report-warns-beijing-faces-tiananmen-like-global-backlashover-virus-idUSKBN22G19C (consulta del 13 de enero de 2021).

${ }^{42}$ Charles Powell, “'Tiene futuro el orden liberal internacional?”, op. cit.

${ }^{43}$ Loc. cit.; Lake, op. cit., 2018.

${ }^{4}$ Jacqueline Anne Braveboy-Wagner (ed.), The Foreign Policies of the Global South, Boulder y Londres, Lynne Rienner Publishers, 2003; Mabel Cristina Thwaites Rey, "Alternativas contrahegemónicas desde el Sur global”, CLACSO, Grupos de Trabajo seleccionados para el periodo 20162019, Clacso, https:/ / www.clacso.org.ar/grupos_trabajo/detalle_gt.php? ficha $=1159 \& \mathrm{~s}=5 \&$ idioma $=\#: \sim:$ text $=$ En $\% 20$ ese $\% 20$ sur $\% 20$ global $\% 20$ incluimos,degradaci $\% \mathrm{C} 3 \% \mathrm{~B} 3 \mathrm{n} \% 20$ econ $\% \mathrm{C} 3 \% \mathrm{~B} 3 \mathrm{mica} \% 2 \mathrm{C} \% 20 \mathrm{pol} \%$ C3\%ADtica\%20y\%20social (consulta del 13 de enero de 2021).

45 Raúl Bernal-Meza y Li Xing, "EE.UU versus China: ¿nueva Guerra Fría?", op. cit. 
gencia de la agenda de la seguridad sanitaria y la situación del institucionalismo y el multilateralismo, con la atención puesta sobre la oMs.

Como lo indica Robert Keohane, la cooperación está en una relación dialéctica con la discordia, en particular entre potencias, y deben entenderse juntas. ${ }^{46}$ Las instituciones no reflejan simplemente las preferencias y el poder de las unidades que las constituyen. Configuran tales preferencias y tal poder. Son constitutivas de los agentes tanto como éstos lo son de aquéllas. ${ }^{47} \mathrm{El}$ institucionalismo liberal las considera como reglas de funcionamiento de la sociedad; recursos de los agentes y actores racionales para obtener sus objetivos. Los Estados las crean para solucionar problemas de acción colectiva, reducir costos de transacción, disminuir incentivos de corrupción, facilitar flujos informacionales, anticipar las sombras del futuro transparentando los retornos y distribuyendo las capacidades en forma más equitativa. El institucionalismo liberal es un acercamiento de la elección racional que entiende a las instituciones como fuerzas estabilizadoras y constringentes, ${ }^{48}$ que permiten enfrentar desafíos globales. La oms es una esfera de autoridad efectiva y tiene una arquitectura institucional específica; la expresión de esta cooperación, con su arquitectura institucional, fue creada para resolver problemas globales, como las epidemias de alcance mundial. ${ }^{49}$

46 Robert O. Keohane, Interdependencia, cooperación y globalismo, México, CIDE, 2009.

47 Robert Keohane, op. cit., en referencia al pensamiento de autores como Richard K. Ashley y John G. Ruggie.

${ }^{48}$ La síntesis corresponde a José Vargas Hernández, "Perspectivas del institucionalismo y neoinstitucionalismo", Ciencia Administrativa, núm. 1, 2008, pp. 47-58.

49 Thomas Legler, "Gobernanza global”, en Thomas Legler, Arturo Santa Cruz y Laura Zamudio González (eds.), Introducción a las Relaciones Internacionales: América Latina y la Política Global, México, Oxford University Press, 2013, pp. 253-266. 
El enfrentamiento en la oms puede situarse como ejemplo de la discordia. Cuando está presente, "las políticas de los agentes entorpecen la realización de las metas de los otros y no se ajustan para hacerlas más compatibles", ${ }^{50}$ porque no aparecen incentivos para que los Estados cambien su comportamiento, lo que se traduce en una ausencia de cooperación internacional que influye sobre las perspectivas generales de la cooperación internacional. El factor "ausencia de incentivo" se debe a la percepción de enfrentamiento entre ambas potencias.

El gobierno de Donald Trump se apartó del pensamiento liberal que pone a las instituciones internacionales en el centro de atención de las relaciones internacionales. ${ }^{51}$ Retiró a su país de la oms, aduciendo que ésta actuó en defensa de China ocultando las responsabilidades del gobierno chino. ${ }^{52} \mathrm{La}$ acusación a la oms se basó en que supuestamente ayudó a China a encubrir los orígenes del virus.

Hay cuatro explicaciones respecto del origen de la Covid-19. En la visión del poder estadounidense, cualquiera de éstas pone en evidencia el carácter cuestionable de la respuesta a la pandemia del régimen chino: 1) fue la mutación de un virus que pasó de una especie animal a otro animal transmisor y, de éste, al ser humano; pero las autoridades chinas ocultaron la información, que permitió la expansión del virus debido a la falta de medidas de contención; 2) el gobierno chino hizo lo posible por identificar el origen del virus, pero se demoró en tomar medidas y denunciarlo a la oms; 3) se trató de un virus sintético, producido en los labo-

${ }^{50}$ Robert O. Keohane, Interdependencia, cooperación y globalismo, op. cit, p. 235.

${ }^{51}$ Robert O. Keohane, Instituciones internacionales y poder estatal. Ensayos sobre teoría de las relaciones internacionales, Buenos Aires, Grupo Editor Latinoamericano, 1993.

52 "Estados Unidos se retira de la oms: Trump notifica oficialmente a Naciones Unidas de la salida de su país”, BBC News, 7 de julio de 2020, https://www.bbc.com/mundo/noticias-internacional-53329647 (consulta del 13 de enero de 2021). 
ratorios militares de Wuhan, cuyo desarrollo se escapó de control; 4) fue una epidemia focalizada en Wuhan, pero las autoridades políticas locales prohibieron la difusión de información y rápidas respuestas médicas de control. ${ }^{53}$ Cualquiera de las dos primeras explicaciones pone en evidencia el férreo control del autoritarismo chino y el ocultamiento de la verdad como política de Estado. La tercera pondría en evidencia que el régimen chino -como sucede con otras grandes potencias- desarrolla armas biológicas. La última explicación mostraría dos situaciones: el impacto negativo del autoritarismo ejercido por el PC sobre las políticas sanitarias y cierta debilidad del control central del Estado sobre las autoridades provinciales. En cuanto a la seguridad nacional, para la administración Trump, un factor fundamental fue "el secretismo de las autoridades chinas (que) convirtió el virus en un peligro de alcance mundial y sin remedio". ${ }^{54}$ Como lo señala Patrick Stewart, los líderes chinos se negaron a cooperar con sus homólogos del G20 y la onU porque temieron ser expuestos y avergonzados. ${ }^{55}$

Otra ilustración de las tensiones sino-estadounidenses en torno al origen de la Covid-19 son las deliberaciones en el Consejo de Seguridad de las Naciones Unidas (CSNU). Según Estados Unidos, habrían permitido descubrir la falta de transparencia china en el manejo inicial del brote y su campaña de desinformación sobre los orígenes del virus, agudizando las críticas internacionales y frustrando los diseños geopolíticos del PCC. El deseo chino de evitar esos resultados y la preocupación de Estados Unidos por exponer su

53 Tom Mitchell et al., "China and Covid-19: What Went Wrong in Wuhan?", Financial Times, 17 de octubre de 2020, https://www.ft.com/ content/82574e3d-1633-48ad-8afb-71ebb3fe3dee (consulta del 13 de enero de 2021).

54 Joan Álvarez, "La diplomacia cultural, el poder blando y los relatos del Covid-19 en la coyuntura inicial de la pandemia”, en Gian Luca Gardini (coord.), op. cit., p. 12.

55 Patrick Stewart, "When the System Fails. COVID-19 and the Costs of Global Dysfunction”, Foreign Affairs, vol. 99, núm. 4, 2020, pp. 40-50. 
mendacidad impidieron al CSNU aprobar una resolución que habría tenido la fuerza vinculante del derecho internacional, lo que hubiera permitido eliminar obstáculos políticos a la cooperación, lo cual habría sido un gran respaldo para la oms y hubiera puesto al multilateralismo por encima de los intereses egoístas de una potencia. Pero el gobierno de Donald Trump tampoco quería eso, porque podía volverse contra Estados Unidos, tal como se advierte ahora en la Corte Internacional de Justicia (CPI), que se abre a investigar los crímenes de guerra en Afganistán. ${ }^{56}$

América Latina no puede asegurar que el virus fue una manipulación del sistema chino de guerra bacteriológica; que Estados Unidos tiene razón en afirmar el origen chino de la epidemia y que hubo manipulación de la denuncia a tiempo y control de la pandemia, o todo lo contrario. La diplomacia sanitaria de Washington, tras haber alineado a gran parte de los países desarrollados de Occidente con su posición, también presionó a otros -los del Sur global-a tomar partido a su favor y en contra de China en el sistema multilateral.

En respuesta, China ha desplegado hacia América Latina, entre otras regiones, una diplomacia médica intensa en la búsqueda de apoyo político. Frente a esta situación, nuestra región tiene escaso margen de acción, pero un alto riesgo de pagar costos políticos y económicos, entre la opción de estar más cerca de Estados Unidos o de China.

\section{Dilemas políticos para América Latina y amenazas a SU MARGEN DE MANIOBRA ANTE LA RIVALIDAD ENTRE POTENCIAS Y LA COVID-19}

La competencia entre grandes poderes y los grados variables de cooperación frente a la pandemia tienen consecuencias en

56 Noticias ONU, "La Corte Penal Internacional autoriza investigar presuntos crímenes de guerra en Afganistán”, 5 de marzo de 2020, https:/ / news. un.org/es/story/2020/03/1470661, (consulta del 13 de enero de 2021. 
las posiciones de Estados Unidos y China hacia América Latina. Según John Mearsheimer, América Latina se está convirtiendo en un escenario de competencia entre ambas potencias. ${ }^{57}$ Mientras que los intereses chinos siguen prioritariamente ocupados de los asuntos económicos, ${ }^{58}$ aquéllos de Estados Unidos priorizan las agendas de seguridad. ${ }^{59}$

En 2020, ambos países compitieron en otros dos temas que se cruzaron con la Covid-19: las redes de internet 5G y la elección de la presidencia del Banco Interamericano de Desarrollo (BID). El gobierno de Trump mantuvo su propio candidato, rompiendo con la tradición que el presidente del banco fuera un latinoamericano, y Mauricio Claver-Carone, un lobista cubano-americano anticastrista, fue electo en septiembre de 2020, con la abstención de Chile, Argentina, Costa Rica y México.

El margen de acción internacional de América Latina es inexistente, debido a su fragmentación política como región; ${ }^{60}$ por la multiplicidad de acuerdos de integración y cooperación y su pérdida de vigencia, como la Unión de Naciones Suramericanas (Unasur) y la Alianza Bolivariana para los Pue-

${ }^{57}$ Leandro Darío, "John Mearsheimer: 'Es posible una guerra entre Estados Unidos y China en 2021'”, Perfil, 25 de julio de 2020, https:/ / www. perfil.com/noticias/actualidad/john-mearsheimer-es-posible-una-gue rra-con-china-en-2021-estados-unidos.phtml (consulta del 18 de septiembre de 2020).

${ }^{58}$ Raúl Bernal-Meza y Li Xing (eds.), op. cit.

${ }^{59}$ Bernabé Malacalza, "La rivalidad Estados Unidos-China en América Latina. ¿Hacia dónde fue la ayuda en la región durante la pandemia?", CENITAL, 5 de julio de 2020, https://www.cenital.com/la-rivali dad-estados-unidos-china-en-america-latina/ (consulta del 18 de septiembre de 2020).

${ }^{60}$ Andrés Malamud y Luis Schenoni, "Latin America is off the Global Stage, and That's OK", Foreign Policy, 10 de septiembre de 2020, https://foreign policy.com/2020/09/10/latin-america-global-stage-imperialism-geopolitics/ (consulta del 13 de enero de 2021). También, Esteban Actis y Bernabé Malacalza, "Autonomía líquida: América Latina y la política exterior en el siglo XxI", Perfil, 26 de octubre de 2020, https://www.perfil.com/noticias/internacio nal/esteban-actis-bernabe-malacalzaautonomia-liquida-america-latina-y-la-po litica-exterior-siglo-xxi.phtml (consulta del 13 de enero de 2021). 
blos de Nuestra América-Tratado de Comercio de los Pueblos (Alba-TCP) ${ }^{61}$ En los años recientes se han desmoronado las instancias regionales y el regionalismo atraviesa una profunda crisis, ${ }^{62}$ que se legitima con discursos conservadores, nacionalistas y/o de extrema derecha ${ }^{63}$ que han conducido a la ausencia de cooperación y coordinación de esfuerzos para enfrentar la Covid-19.

Para Celi y Grabendorff, la pandemia ha afectado el ámbito de la seguridad, condicionado por situaciones de conflicto a nivel interno de los países y por la situación de las relaciones entre vecinos. ${ }^{64}$ La salud, como parte de la seguridad nacional, ha tenido respuestas nacionalistas, al igual que ocurrió en Estados Unidos y la Unión Europea. ${ }^{65}$ El nacionalismo y la lealtad al propio Estado han demostrado estar profundamente arraigados en las sociedades y los sistemas políticos, ${ }^{66}$ no sólo en América Latina sino en el mundo, lo que ha contribuido a la debilidad de las respuestas concertadas internacional o regionalmente, restando apoyo a las instituciones multilaterales como la oms. Los países sudamericanos adoptaron la política internacional que ini-

${ }^{61}$ Carlos Fortín, Jorge Heine y Carlos Ominami, "Latinoamérica: no alineamiento y la segunda Guerra Fría”, Foreign Affairs Latinoamérica, vol. 20, núm 3, julio-septiembre de 2020, pp. 107-115; Pablo Celi De la Torre y Wolf Grabendorff, "Crisis y perspectivas de la gobernanza y la seguridad regional en América Latina”, Pensamiento Propio, núm. 51, 2020, pp. 267277; Consuelo Silva, Ariel Noyola y Julian Kan (coords.), América Latina: una integración regional fragmentada y sin rumbo, Buenos Aires, Clacso, 2019; José A. Sanahuja, "La crisis de la integración y el regionalismo en América Latina: giro liberal-conservador y contestación normativa", en Manuela Mesa (coord.), Ascenso del nacionalismo y el autoritarismo en el sistema internacional. Anuario 2018-2019, Madrid, Centro de Educación e Investigación para la Paz, 2019, pp. 107-126.

${ }^{62}$ Carlos Fortín, Jorge Heine y Carlos Ominami, op. cit.

${ }^{63}$ José A. Sanahuja, op. cit., 2019, p. 122.

64 Pablo Celi De la Torre y Wolf Grabendorff, op. cit.

${ }^{65}$ G. John Ikenberry, op. cit.

${ }^{66}$ Gian Luca Gardini, "El Covid-19 y la relevancia de la teoría política y de las Relaciones Internacionales", en Gian Luca Gardini (coord.), op. cit., pp. 55-59. 
ciaron Estados Unidos y la Unión Europea: la de "sálvese quien pueda”. El fortalecimiento de políticas nacionalistas y xenófobas; la fuerte recuperación de la mirada hobbesiana de las relaciones internacionales; el realismo duro del Estado y la imposición del poder del Leviatán sobre las sociedades civiles no han dejado margen de acción a las sociedades nacionales que enfrentan aisladas las decisiones unilaterales de los gobiernos.

Sin embargo, desunida, América Latina corre el riesgo de verse obligada a tomar partido en la rivalidad política, estratégica y tecnológica entre las dos potencias.

¿Puede adoptar América Latina una posición crítica frente a Estados Unidos?

La posición de Estados Unidos hacia la presencia de China en América Latina se ha ido radicalizando. Barack Obama (2009-2017) toleró la presencia económica china en América Latina, pero las visitas de los secretarios de Estado y de Defensa de Donald Trump a la región, denunciando el riesgo de esa presencia, dejaron un mensaje de advertencia: la posición tradicional de las cancillerías latinoamericanas de querer tener buenas relaciones con Estados Unidos y China es inaceptable y ha llegado la hora de escoger. ${ }^{67}$ Estados Unidos no les ha pedido aliarse con su posición, que exige a China pagar por su responsabilidad en la epidemia, pero sí lo ha solicitado a Occidente de manera general y dos de sus aliados, el Reino Unido y Francia, estuvieron con Estados Unidos en contra de China en el cSNU.

En materia de tecnología, la política de la administración Trump fue desintegradora, pese a la realidad de un mercado sino-estadounidense estrechamente interrelacionado. Las exportaciones estadounidenses a China aumentaron 527\% desde 2001 y, en 2018, China fue el mayor proveedor de bie-

${ }^{67}$ Carlos Fortín, Jorge Heine y Carlos Ominami, op. cit. 
nes de Estados Unidos. China es el tercer mercado de exportación de Estados Unidos y de 2006 a 2016, el de mayor crecimiento, con una expansión de $115 \% .{ }^{68}$ Confluyen en esa posición desintegradora tres razones: el rechazo a China, la disposición al conflicto con este país y la visión antiglobalización. La estrategia ha sido romper los lazos con China y obligar al resto del mundo a hacer lo mismo, creando una división entre dos bandos. Aunque la administración Trump pidió a 61 países que prohibieran las redes de internet $5 \mathrm{G}$ de Huawei, sólo tres aliados cercanos de Estados Unidos lo han hecho. ${ }^{69}$ En nuestra región, el gobierno estadounidense amenazó a Brasil con "consecuencias" si optaba por las redes chinas ${ }^{70}$ y presionó a otros gobiernos latinoamericanos. $^{71}$

Para América Latina, el principal problema de America First es que limita los márgenes de acción internacional, por su impacto sobre el desarrollo económico, en un contexto de crisis social, sanitaria y económica. Si bien es posible que con Joseph Biden, el presidente demócrata electo en noviembre de 2020, el fortalecimiento del oLI retorne como

${ }^{68}$ David A. Lake, op. cit.

${ }^{69}$ Fareed Zakaria, op. cit. El autor no nombra a estos países. Según la información disponible, éstos son Gran Bretaña, Australia y Japón.

${ }^{70}$ Renato Santino, "Embaixador dos EUA diz que Brasil 'terá consequências' se permitir Huawei no 5G", Olhar Digital, 30 de julio de 2020, https://olhardigital.com.br/noticia/embaixador-dos-eua-diz-que-brasiltera-consequencias-se-permitir-huawei-no-5g/104348 (consulta del 18 de septiembre de 2020).

${ }^{71}$ Estados Unidos ofreció a Chile financiamiento para que el cable que conectará a Valparaíso con Shanghái, pase primero por Auckland y Sidney y de allá a Japón, e impedir así la conexión de Chile con China, como estación para las comunicaciones con Asia. "EE.UU ofrece financiar el cable chileno a Asia", Diario Financiero, 30 de agosto de 2020, https:// www.df.cl/noticias/df-mas/por-dentro/ee-uu-ofrece-financiar-el-cablechileno-a-asia/2020-08-27/214434.html (consulta del 18 de septiembre de 2020); "América Latina, un campo de batalla de la guerra fría entre China y EE.Uu.”, $D W, 30$ de julio de 2020, https:/ / www.dw.com/es/am\%C3\%A9ri ca-latina-un-campo-de-batalla-de-la-guerra-fr\% C3\% ADa-entre-china-yeeuu/a-54386081 (consulta del 13 de enero de 2021). 
prioridad internacional, la dirección que pretende impulsar parece dirigida hacia una forma de multilateralismo que haga frente al desafío chino y no a una dimensión más amplia. ${ }^{72}$ Su llamado a una alianza multilateral de democracias, el regreso a la supuesta defensa de los derechos humanos y el combate a los gobiernos autoritarios, dirigido en contra de China, también podrían transformarse en condicionantes para los países latinoamericanos. A las advertencias que ya les había expresado Trump sobre las relaciones económicas y financieras con China, ahora podrían agregarse temas políticos, ideológicos y de otras agendas internacionales del internacionalismo liberal, como los derechos humanos y el medio ambiente. América Latina aparece como espacio político de extensión de las agendas estadounidenses sobre China.

América Latina no tiene capacidad política para adoptar una posición crítica frente a Estados Unidos respecto de la rivalidad sino-estadounidense en cuanto a la hegemonía de las esferas de influencia ni en lo que se refiere a la confrontación sobre el origen de la Covid-19 y su tratamiento en el marco de la oms. Tampoco la tendrá frente a la política anticipada por el presidente electo, Joseph Biden. La región no habla con una sola voz frente a Estados Unidos porque los acuerdos de gobernanza regionales expresan una diversidad de visiones y posiciones de economía política internacional; sus países han perdido la fe en trabajar juntos, y en la integración y cooperación regionales, lo cual también perjudica su relación con China.

\section{¿Puede adoptar América Latina una posición crítica frente a China?}

Desde la perspectiva de la economía política internacional, la posición de los países latinoamericanos es de gran debilidad. La estructura de relaciones económicas centro-periferia que

72 Joseph R. Biden, "Why America Must Lead Again”, Foreign Affairs, vol. 99, núm. 2, 2020, pp. 64-76. 
China ha construido con la región ha hecho que la vulnerabilidad económica latinoamericana se haya desplazado de Estados Unidos hacia ese país como la potencia económica hegemónica. Siete de los diez países sudamericanos tienen a China como el principal socio de sus exportaciones: Argentina, Brasil, Chile, Perú, Ecuador, Uruguay y Venezuela; mientras que China es el segundo socio comercial de Bolivia y Colombia. El comercio entre China y Latinoamérica ha crecido en forma vertiginosa: de 10000 millones de dólares estadounidenses (USD) en 2000, a 307000 millones en 2018. ${ }^{73}$ Venezuela, Brasil, Argentina, Ecuador y Bolivia suman acreencias cuyos compromisos financieros totales contraídos con las entidades públicas chinas ascendían a más de 133000 millones de dólares. La Comisión Económica de las Naciones Unidas para América Latina y el Caribe (Cepal) estimó que los compromisos prestatarios a los gobiernos de América Latina y el Caribe, financiados por China en el periodo 2005-2016, ascendieron a más de 141000 millones de USD, cifra superior al monto recibido de los organismos multilaterales de crédito. ${ }^{74}$ Los flujos financieros de la banca china hoy son superiores a los del Banco Mundial, el Fondo Monetario Internacional (FMI), el Banco Interamericano de Desarrollo (BID) y el Banco de Desarrollo de América Latina juntos. ${ }^{75}$ América Latina tiene una dependencia comercial y financiera cuyas debilidades se trasladan al campo de la política, ${ }^{76}$ lo que hace que le resulte difícil adoptar una posición crítica frente a Beijing.

${ }^{73}$ Carlos Fortín, Jorge Heine y Carlos Ominami, op. cit.

${ }^{74}$ Este monto es superior al financiamiento que América Latina y el Caribe recibió en ese periodo de instituciones como el Banco Interamericano de Desarrollo (BID), el Banco Mundial y el Banco de Desarrollo de América Latina (CAF), que otorgaron créditos soberanos a la región por 117800 millones de USD, 85500 millones de USD y 55100 millones de USD, respectivamente. Cepal, Explorando nuevos espacios de cooperación entre América Latina y el Caribe y China, 2018, p. 22.

${ }^{75}$ Carlos Fortín, Jorge Heine y Carlos Ominami, op. cit.

${ }^{76}$ Raúl Bernal-Meza and Li Xing (eds.), op. cit., y Eduardo Oviedo (comp.), Inversiones de China, Corea y Japón en Argentina: análisis general y estudio de casos, Rosario, unR Editora, 2017. 
Además, China ha desarrollado una "diplomacia de las mascarillas" en el contexto de la Covid-19 que, a través de la ayuda en equipamiento sanitario, busca evitar o disminuir el deterioro de su imagen política internacional como responsable de la expansión de la epidemia. Según el Departamento de Estado, solo $9 \%$ de la ayuda que Estados Unidos envió al mundo fue dirigida a América Latina y el Caribe: un total de 83 millones de USD, concentrada en 3/4 partes en el Caribe y Centroamérica. En contraste, China llevaba desembolsados, hasta julio de 2020, un total de 665 millones de USD. Chile, México y Argentina, que recibieron muy poca ayuda de Estados Unidos, fueron los más beneficiados por China. ${ }^{77}$ Otras investigaciones señalan que los determinantes políticos tuvieron un papel importante en estas donaciones, como el de la situación respecto a la asociación con China y la política de una China

Si bien existe un foro regional de relaciones (China-Celac) no ha sido a través de éste que Beijing ha llevado a cabo la cooperación hacia la región, lo que reafirma la idea de que no apoya bloques regionales para resolver los problemas sanitarios en esta parte del mundo y que su estrategia sigue siendo la de relaciones país a país. ${ }^{78}$

Esta tendencia no favorece a América Latina. Méndez y Turzi afirman que la escasez de agencia (capacidad de acción y decisión), así como de construcción social en términos regionales, y un consecuente déficit institucional en sus relaciones exteriores, caracteriza a los países de la región y da lugar a una inadecuada reacción al poder chino. ${ }^{79} \mathrm{El}$ crecimiento de la influencia económica china, principalmente en Sudamérica, no ha conducido a la adopción de posiciones

77 Bernabé Malacalza, op. cit.

78 Tal como fue la conclusión de Raúl Bernal-Meza y Li Xing (eds.), op. cit.

79 "A dearth of regional agency and social construction, and a consequent institutional deficit in foreign relations, characterizes Latin America and its inadequate reaction to Chinese agency", Álvaro Méndez y Mariano Turzi, op. cit. 
comunes para aprovechar la disminución de la influencia económica y política estadounidense vis-à-vis la dependencia y autonomía en los asuntos internacionales. ${ }^{80}$ La explicación es clara: las instituciones multilaterales son lo que los Estados y sus líderes hacen de ellas y los países latinoamericanos no han optado por el multilateralismo regional.

Con la pandemia de Covid-19, el principal peligro para América Latina no son las consecuencias de vidas perdidas, crisis económica y la pérdida de empleos en actividades que no se recuperarán en el corto o mediano plazo, sino la imagen de que gobiernos autoritarios, para el caso, China, responden más eficientemente a los desafíos ocasionados por la pandemia que las democracias occidentales: Estados Unidos y Europa occidental. El atractivo de China, como modelo político a emular, proviene de su capacidad de respuesta para derrotar al virus y relanzar el crecimiento económico, mientras que las democracias fallaron a sus ciudadanos. ${ }^{81}$ Esta constatación se agrega a la imagen de China como modelo de desarrollo: un ejemplo exitoso que nuestra región descubrió al mismo tiempo que se convenció de su industrialización del fracaso. ${ }^{82}$ Pero también debe considerarse que el régimen chino no fue capaz de procesar la información crítica sobre la dimensión de la epidemia y fue asombroso ver cómo su gobierno inicialmente manejó mal la situación, ${ }^{83}$ ayudando a debilitar a la oms.

Ante las presiones recibidas a causa de la rivalidad sinoestadounidense, analistas latinoamericanos han propuesto una política de concertación regional: no tomar partido ni alinearse. ${ }^{84}$ Pero la realidad mundial señala que las esferas de influencia han regresado y reaparece la mención de América Latina como parte de la esfera de influencia estadouni-

${ }^{80}$ Raúl Bernal-Meza y Li Xing (eds.), op. cit.

${ }^{81}$ Ian Bremmer, "Coronavirus and the World Order to Come", Horizons, núm. 16, 2020, pp. 14-23.

${ }^{82}$ Bernal-Meza and Li Xing (eds.), op. cit.

${ }^{83}$ Minxin Pei, op. cit.

${ }^{84}$ Carlos Fortín, Jorge Heine y Carlos Ominami, op. cit. 
dense. ${ }^{85}$ Frente a ello y ante las respuestas chinas, y a pesar de la crisis provocada por la Covid-19, los países de la región no han manifestado ninguna vocación por la concertación regional. ${ }^{86}$ Como sucede también en el resto del mundo, los gobiernos latinoamericanos han perdido la fe en el valor de trabajar juntos.

No hay miradas comunes sobre los riesgos y desafíos que plantea China; ${ }^{87}$ tampoco sobre el impacto de la rivalidad y las crecientes tensiones sino-estadounidenses o sobre los condicionantes de la política de Washington que, como coletazos de su enfrentamiento con China, se desparramen sobre nuestra región. Finalmente, esto se debe a que las políticas exteriores de los países latinoamericanos siguen teniendo a Estados Unidos como el telón de fondo de sus propias diferencias. ${ }^{88}$

\section{Conclusiones}

El deterioro del oIL y del multilateralismo, debido a la rivalidad sino-estadounidense acentuada por la Covid-19, son gra-

${ }^{85}$ Graham Allison, "The New Spheres of Influence", art. cit.; Li Xing, "China's Global Rise and Neoimperialism: Attitudes and Actualities.", op. cit.

${ }^{86}$ Carlos Malamud, "Coordinación regional frente al COVID-19 en América Latina”, Real Instituto Elcano, 3 de junio de 2020, https://blog. realinstitutoelcano.org/coordinacion-regional-frente-al-covid-19-en-america-latina/ (consulta del 18 de septiembre de 2020).

${ }^{87}$ Raúl Bernal-Meza, "China en América Latina. Política exterior, discurso y fundamentos: diplomacia pública y percepciones en la región", en Eduardo Pastrana Buelvas y Hubert Gehring (eds.), La proyección de China en América Latina y el Caribe, Bogotá, Editorial Pontificia Universidad Javeriana, 2017, pp. 171-187; Raúl Bernal-Meza, "La heterogeneidad de la imagen de China en la política exterior latinoamericana. Perspectivas para la concertación de políticas", Comentario Internacional, núm. 14, 2014, pp. 113-134.

88 Amado Luiz Cervo, Relações Internacionais da América Latina, São Paulo, Editora Saraiva, 2014; Mariano Turzi, "Relaciones América LatinaEstados Unidos", en Thomas Legler, Arturo Santa Cruz y Laura Zamudio González (eds.), op. cit., pp. 184-194. 
ves problemas para América Latina, porque constituyen los entornos internacionales de los cuales depende para su inserción internacional. Debido a la ausencia de capacidades de poder e influencia, suele depositar en el multilateralismo sus expectativas políticas internacionales. En el multilateralismo, las enormes asimetrías de poder pueden enfrentarse de manera parcial mediante coaliciones y alianzas. El regreso al multilateralismo que propone Joseph Biden mantiene a China como el desafío al orden liberal. Desde esta perspectiva, podríamos asistir a un nuevo conflicto entre las democracias liberales y el modelo chino de capitalismo, y una lucha global de las primeras en contra de la violación de los derechos humanos y el autoritarismo. Estados Unidos comienza a presionar con la política de las alineaciones obligatorias y China pide no obligar a los países a tomar partido por la competencia tecnológica entre Washington y Beijing.

Es el regreso de la rivalidad entre grandes potencias. ${ }^{89}$ Un conflicto imperialista intracapitalista por el dominio económico, tecnológico y político. La limitación de la cooperación estadounidense en alta tecnología empuja a China a desarrollar sus propios sectores, lo que crea una realidad virtual de "esferas de interés" tecnológicas que está dividiendo al mundo. En este contexto, las tensiones entre ambas potencias se han trasladado también a la agenda de la salud.

A pesar de la creciente importancia de la inversión y el comercio chinos en América Latina -desplazando o reemplazando a los de Estados Unidos- la ayuda frente a la Covid-19 no se ha reflejado en la transición hegemónica económica. ${ }^{90}$

${ }^{89}$ Mariano Turzi, "The Age of Pressure Politics?”, Global Policy, 6 de agosto de 2020, https: / www.globalpolicyjournal.com/blog/06/08/2020/ age-pressure-politics (consulta del 25 de septiembre de 2020); R. BernalMeza and Li Xing, "Ee.uU. versus China: ¿nueva Guerra Fría?”, op. cit.; G. John Ikenberry, op. cit., 2020.

${ }^{90}$ Luis L. Schenoni, "Bipolarity or Hegemony? Latin America's Dilemma for the 21st Century”. E-International Relations, 24 de febrero de 2019, https://www.e-ir.info/pdf/77803 (consulta del 15 de enero de 2021) y Francisco Urdínez et al., "Chinese Economic Statecraft and US Hegemony 
Con una rivalidad creciente, donde ambas potencias son más proclives a la confrontación y ante generalizadas respuestas nacionalistas para enfrentar la pandemia, el sistema internacional parece dirigirse hacia un mundo más anárquico. ${ }^{91}$ La experiencia de la crisis de los años de 1930 demostró que se necesitaba una potencia dominante para proporcionar los bienes públicos globales; ${ }^{92}$ y eso es lo que hoy parece ausente. El mundo carece de liderazgo global o soluciones compartidas. Ningún Estado o alianza de Estados está dispuesto o es capaz de proporcionar bienes públicos globales ${ }^{93}$ y retorna la importancia del poder militar. ${ }^{94}$ Éste es el peor escenario para América Latina, que ha desechado por ahora la cooperación común posible.

La pandemia puso de manifiesto los límites del sistema multilateral y los costos de su fracaso. ${ }^{95} \mathrm{Su}$ destino es una de las incógnitas que develará el orden que viene. Las opiniones sobre su reconstrucción y fortalecimiento son opuestas. Mucho dependerá del retorno -o no- de Estados Unidos al internacionalismo liberal. ${ }^{96}$ Pero será la rivalidad estratégica, militar, económica, financiera, tecnológica e ideológica entre China y Estados Unidos la que dará forma a sus relaciones con terceros países y su estrategia con el multilateralismo. ${ }^{97}$

China emerge como poder y crecerá su imagen en la mirada de los países en desarrollo como modelo atractivo de

in Latin America”, Latin American Politics and Society, vol. 58, núm 4, 2016 , pp. 3-30.

91 Kevin Rudd, op. cit.

${ }^{92}$ Charles P. Kindleberger, op. cit.; Robert Gilpin, op. cit.

93 Jeffrey D. Sachs, "COVID-19 and Multilateralism”, Horizons, núm. 16, 2020, pp. 30-38.

${ }_{94}$ Robert Kagan, El retorno de la historia y el fin de los sueños, Barcelona, Taurus, 2008.

95 Patrick Stewart, op. cit.

96 Véase al respecto Daniel W. Drezner, Ronald R. Krebs y Randall Schweller, op. cit.; Graham Allison, "The New Spheres of Influence”, art. cit.; G. John Ikenberry, op. cit., Alexander Cooley y Daniel H. Nexon, op. cit. y Richard Haass, op. cit.

97 Kevin Rudd, op. cit. 
capacidad de gestión en seguridad sanitaria y economía. La crisis de la Covid-19 ha mostrado una China más confiada, que ve la oportunidad de cambiar el orden global en su beneficio. Esa confianza nace de la mayor dependencia internacional que el mundo tiene de ella y de la falta de estrategia y liderazgo de las potencias occidentales, en particular de Estados Unidos. Si comparamos los aportes, el papel de China en América Latina se advierte más voluntarioso que aquel de Estados Unidos, aun cuando su forma de cooperación sanitaria ha comenzado a ser cuestionada. ${ }^{98}$

Según Patrick Stewart, "la pandemia parece haber expuesto al orden liberal y a la comunidad internacional como espejismos, incluso cuando demuestra las terribles consecuencias de la vacilante cooperación global". ${ }^{99}$ La ausencia de respuestas colectivas pone en evidencia la crisis del multilateralismo. El poder del Estado, que mira el sistema como un orden anárquico, está de regreso, confirmando la argumentación de Kenneth Waltz de que vivimos en un mundo de perpetua anarquía internacional. ${ }^{100}$ Enfrentadas ambas consecuencias, cuyo telón de fondo es la competencia y rivalidad entre las dos grandes potencias, el destino de nuestra región se ve mucho más incierto.

\section{REFERENCIAS BIBLIOGRÁFICAS}

Actis, Esteban y Bernabé Malacalza, “Autonomía líquida: América Latina y la política exterior en el siglo xxı”, Perfil, 26 de octubre de 2020, https://www.perfil.com/noticias/internacio nal/esteban-actis-bernabe-malacalzaautonomia-liquida-ameri ca-latina-y-la-politica-exterior-siglo-xxi.phtml

98 Diego Telias y Francisco Urdínez, op. cit.

99 "The pandemic seems to have exposed the liberal order and the international community as mirages, even as it demonstrates the terrible consequences of faltering global cooperation" (traducción propia en texto). Patrick Stewart, op. cit.

${ }^{100}$ Kenneth Waltz, op. cit. 
Allison, Graham, "The New Spheres of Influence: Sharing the Globe with Other Great Powers", Foreign Affairs, vol. 99, núm. 2, 2020, pp. 30-40.

Allison, Graham, Destined for War: Can America and China Escape Thucydides's Trap?, Nueva York, Houghton Mifflin Harcourt, 2017. Álvarez, Joan, "La diplomacia cultural, el poder blando y los relatos del Covid-19 en la coyuntura inicial de la pandemia", en Gian Luca Gardini (coord.), El mundo antes y después del Covid-19, Salamanca, Instituto Europeo de Estudios Internacionales, 2020, pp. 12-15.

"América Latina, un campo de batalla de la guerra fría entre China y EE.UU.", Dw, 30 de julio de 2020, https://www.dw.com/es/ am\% C3\% A9rica-latina-un-campo-de-batalla-de-la-guerrafr\%C3\%ADa-entre-china-y-eeuu/a-54386081

Bernal-Meza, Raúl, "La heterogeneidad de la imagen de China en la política exterior latinoamericana. Perspectivas para la concertación de políticas”, Comentario Internacional, núm. 14, 2014, pp. 113-134.

Bernal-Meza, Raúl, "China en América Latina. Política exterior, discurso y fundamentos: diplomacia pública y percepciones en la región”, en Eduardo Pastrana Buelvas y Hubert Gehring (eds.), La proyección de China en América Latina y el Caribe, Bogotá, Editorial Pontificia Universidad Javeriana, 2017, pp. 171-187.

Bernal-Meza, Raúl, "Dos aportes teóricos latinoamericanos de relaciones internacionales y su utilización por el pensamiento chino contemporáneo: los casos de Prebisch y Escudé”, Revista Estudios Sociales, núm. 64, 2018, pp. 75-87.

Bernal-Meza, Raúl, “¿Orden regulado por la anarquía?”, Clarín, 19 de abril de 2020, https:/ /www.clarin.com/opinion/-ordenregulado-anarquia-_0_mqSkpYYXW.html

Bernal-Meza, Raúl y Li XING, "Ee.uU. versus China: ¿nueva Guerra Fría?", Clarin, 2 de agosto de 2020, https:/ / www.clarin.com/ opinion/ee-uu-versus-china-nueva-guerra-fria-_0_snq8oxGdL. html

Bernal-Meza, Raúl y Li XING (eds.), China-Latin America Relations in the $21^{\text {st }}$ Century. The Dual Complexities of Opportunities and Challenges, Nueva York, Palgrave Macmillan, 2020. 
Biden, Joseph R., "Why America Must Lead Again”, Foreign Affairs, vol. 99, núm. 2, 2020, pp. 64-76.

Braveboy-Wagner, Jacqueline Anne (ed.), The Foreign Policies of the Global South, Boulder y Londres, Lynne Rienner Publishers y Clacso, 2003.

Bremmer, Ian, "Coronavirus and the World Order to Come", Horizons, núm. 16, 2020, pp. 14-23.

Celi de la Torre, Pablo y Wolf Grabendorff, "Crisis y perspectivas de la gobernanza y la seguridad regional en América Latina”, Pensamiento Propio, núm. 51, 2020, pp. 267-277.

Cervo, Amado Luiz, Relações internacionais da América Latina, São Paulo, Editora Saraiva, 2014.

Cooley, Alexander y Daniel H. Nexon, "How Hegemony Ends the Unraveling of American Power”, Foreign Affairs, vol. 99, núm. 4, 2020, pp. 143-155.

DARío, Leandro, "John Mearsheimer: 'Es posible una guerra entre Estados Unidos y China en 2021'”, Perfil, 25 de julio de 2020, https://www.perfil.com/noticias/actualidad/john-mearshei mer-es-posible-una-guerra-con-china-en-2021-estados-unidos. phtml

Drezner, Daniel W., Ronald R. Krebs y Randall Schweller, "The End of Grand Strategy”, Foreign Affairs, vol. 99, núm. 3, 2020, pp. 107-117.

Dussel Peters, Enrique , 'Las 'nuevas relaciones triangulares' de América Latina y el Caribe: entre 'el proceso de globalización con características chinas' y tensiones con Estados Unidos”, en Wolf Grabendorff y Andrés Serbin (eds.), Los actores globales y el (re)descubrimiento de América Latina, Barcelona, Icaria Editorial/ CRIES, 2020, pp. 133-144.

"EE.UU. ofrece financiar el cable chileno a Asia", Diario Financiero, 30 de agosto de 2020, https:/ / www.df.cl/noticias/df-mas/pordentro/ee-uu-ofrece-financiar-el-cable-chileno-a-asia/2020-0827/214434.html

"Estados Unidos se retira de la oms: Trump notifica oficialmente a Naciones Unidas de la salida de su país”, $B B C$ News, 7 de julio de 2020, https:/ / www.bbc.com/mundo/noticias-internacional53329647 
"Exclusive: Internal Chinese Report Warns Beijing Faces Tiananmen-Like Global Backlash over Virus", Reuters, 4 de mayo de 2020, https://www.reuters.com/article/us-health-coronaviruschina-sentiment-ex/exclusive-internal-chinese-report-warnsbeijing-faces-tiananmen-like-global-backlash-over-virus-idUS KBN22G19C

Explorando nuevos espacios de cooperación entre América Latina y el Caribe y China, Cepal, 2018.

Fisher, Matthew, "Commentary: A New 'Cold War' is Developing between China and the U.S.”, Global News, 10 de agosto de 2020, https:/ / globalnews.ca/news/7256840/china-us-cold-war/

Fortín, Carlos, Jorge Heine y Carlos Ominami, "Latinoamérica: no alineamiento y la segunda Guerra Fría”, Foreign Affairs Latinoamérica, vol. 20, núm. 3, julio-septiembre de 2020, pp. 107-115.

Fusaro, Lorenzo, "Gramsci's Concept of Hegemony at the National and International Level", presentación durante la conferencia anual de la International Initiative for Promoting Political Economy (IIPPE), Rétino, septiembre de 2010, https://www. researchgate.net/publication/315643553_Gramsci's_concept_of_hegemony_at_the_national_and_international_level

Gaens, Bart y Ville Sinkkonen (eds.), Great-Power Competition and The Rising US-China Rivalry, Helsinki, Finnish Institute of International Affairs, 2020, pp. 57-71.

Gaddis, John L., Strategies of Containment: A Critical Appraisal of Postwar American National Security Policy, Nueva York, Oxford University Press, 1982.

Gaddis, John L., The United States and the Origins of the Cold War, 1941-1947, Nueva York, Columbia University Press, 2001.

Gaddis, John L., On Grand Strategy, Nueva York, The Penguin Press, 2018.

GARDini, Gian Luca, "Introducción: un marco para el análisis y la reflexión”, en Gian Luca Gardini (coord.), El mundo antes y después del Covid-19, Salamanca, Instituto Europeo de Estudios Internacionales, 2020, pp. 1-6.

GARDini, Gian Luca, "El Covid-19 y la relevancia de la teoría política y de las Relaciones Internacionales", en Gian Luca Gardini 
(coord.), El mundo antes y después del Covid-19, Salamanca, Instituto Europeo de Estudios Internacionales, 2020, pp. 55-59.

Gilpin, Robert, The Political Economy of International Relations, Cambridge, University Press, 1987.

GiLPIn, Robert, War and Change in World Politics, Cambridge, University Press, 1981.

HaAss, Richard, "Hasta el límite con China", Project Syndicate, 13 de agosto de 2020, https:/ /www.project-syndicate.org/commentary/cold-war-or-managed-competition-with-china-by-richardhaass-1-2020-08/spanish

Heine, Jorge, “¿Un mundo (y un orden mundial) al revés?”, en Gian Luca Gardini (coord.), El mundo antes y después del Covid-19, Salamanca, Instituto Europeo de Estudios Internacionales, 2020, pp. 25-29.

Hobson, John, Imperialism: A Study, Nueva York, James Pott \& Company, 1902.

Hung, Ho-Fung, "The US-China Rivalry is About Capitalist Competition", Jacobin, 11 de julio de 2020, https://www.jacobinmag. com/2020/07/us-china-competition-capitalism-rivalry

Ikenberry, G. John, "The Next Liberal Order: The Age of Contagion Demands More Internationalism, Not Less”, Foreign Affairs, vol. 99, núm. 4, 2020, pp. 133-142.

Ikenberry, G. John, "La crisis del orden liberal mundial”, Anuario Internacional СІDОв 2018, 2018, pp. 29-36.

Ikenberry, G. John, "The Future of the Liberal World Order", Foreign Affairs, vol. 90, núm. 3, 2011, pp. 56-68.

IkenberRy, G. John, "The Rise of China and the Future of the West", Foreign Affairs, vol. 87, núm. 1, 2008, pp. 23-37.

KAGAN, Robert, El retorno de la historia y el fin de los sueños, Barcelona, Taurus, 2008.

KARA A., Ramón, "Plan de la oms de acceso mundial a la vacuna contra el Covid-19 suma adeptos, pero no atrae a EE.UU. ni China", Emol, 21 de septiembre de 2020, https://www.emol.com/ noticias/Internacional/2020/09/21/998510/OMS-plan-vacu na-coronavirus.html

Kemp, John, "United States and China Enter a New Cold War: Kemp", Reuters, 22 de julio de 2020, https:/ /www.reuters.com/ 
article/us-global-politics-kemp-column/united-states-and-chi na-enter-a-new-cold-war-kemp-idUSKCN24N1MT.

Kennedy, Paul, The Rise and Fall of the Great Powers, Nueva York, Random House, 1987.

Keohane, Robert O., Interdependencia, cooperación y globalismo, México, CIDE, 2009.

Keohane, Robert O., Instituciones internacionales y poder estatal. Ensayos sobre teoría de las relaciones internacionales, Buenos Aires, Grupo Editor Latinoamericano, 1993.

Kindleberger, Charles P., The World in Depression, 1929-1939, Berkeley, University of California Press, 1973.

Kissinger, Henry, "Kissinger Warns U.S. and China Must Set Limits to Avoid a Blowup", Bloomberg News, 7 de octubre de 2020, https:/ / www.bloomberg.com/news/articles/2020-10-07/kissinger-warns-u-s-and-china-must-set-limits-to-avoid-a-blowup

Lake, David A., "Economic Openness and Great Power Competition: Lessons for China and the United States", The Chinese Journal of International Politics, vol. 11, núm. 3, 2018, pp. 237-270.

Legler, Thomas, "Gobernanza global”, en Thomas Legler, Arturo Santa Cruz y Laura Zamudio González (eds.), Introducción a las Relaciones Internacionales: América Latina y la política global, México, Oxford University Press, 2013, pp. 253-266.

Lenin, Vladimir, Imperialism, the Highest Stage of Capitalism, Moscú, Progress Publishers, 1917.

Malacalza, Bernabé, "La rivalidad Estados Unidos-China en América Latina. ¿Hacia dónde fue la ayuda en la región durante la pandemia?", Cenital, 5 de julio de 2020, https:/ /www.ceni tal.com/la-rivalidad-estados-unidos-china-en-america-latina/

Malamud, Andrés y Luis Schenoni, "Latin America is off the Global Stage, and That's OK", Foreign Policy, 10 de septiembre de 2020, https://foreignpolicy.com/2020/09/10/latin-americaglobal-stage-imperialism-geopolitics/

Malamud, Carlos, "Coordinación regional frente al COVID-19 en América Latina", Real Instituto Elcano, 3 de junio de 2020, https://blog.realinstitutoelcano.org/coordinacion-regionalfrente-al-covid-19-en-america-latina/ 
Mearsheimer, John, The Tragedy of Great Power Politics, Nueva York, Norton \& Company, 2001.

Méndez, Álvaro y Mariano Turzi, The Political Economy of China-Latin America Relations: The AIIB Membership, Cham, Springer Nature, 2020.

Mitchell, Tom, et al., "China and Covid-19: What Went Wrong in Wuhan?”, Financial Times, 17 de octubre de 2020, https://www. ft.com/content/82574e3d-1633-48ad-8afb-71ebb3fe3dee

Morgenthau, Hans J., Politics Among Nations, Nueva York, Knopf, 1948.

Naciones Unidas, "La Corte Penal Internacional autoriza investigar presuntos crímenes de guerra en Afganistán”, Noticias onU, 5 de marzo de 2020, https:/ / news.un.org/es/story/2020/ 03/1470661

Oviedo, Daniel (comp.), Inversiones de China, Corea y Japón en Argentina: análisis general y estudio de casos, Rosario, UNR Editora, 2017.

PeI, Minxin, "China's Coming Upheaval Competition, the Coronavirus, and the Weakness of Xi Jinping", Foreign Affairs, vol. 99, núm. 3, 2020, pp. 82-95.

Pompeo, Michael R., "Secretary Michael R. Pompeo with Julian Reichelt of BILD-TV", Departamento de Estado de EE.Uu., 13 de abril de 2020, https://www.state.gov/secretary-michael-r-pom peo-with-julian-reichelt-of-bild-tv/

Powell, Charles, “¿Tiene futuro el orden liberal internacional?”, Real Instituto Elcano, 29 de junio de 2017, http:/ /www.realinsti tutoelcano.org/wps/portal/rielcano_es/contenido?WCM_ GLOBAL_CONTEXT=/elcano/elcano_es/zonas_es/ari562017-powell-tiene-futuro-orden-liberal-internacional

Rudd, Kevin, "The Coming Post-COVID Anarchy The Pandemic Bodes Ill for Both American and Chinese Power - and for the Global Order", Foreign Affairs, 6 de mayo de 2020, https: / www. foreignaffairs.com/articles/united-states/2020-05-06/comingpost-covid-anarchy .

SAchs, Jeffrey D., "COVID-19 and Multilateralism", Horizons, núm. 16, 2020, pp. 30-38. 
SAnahuja, José A., "La crisis de la integración y el regionalismo en América Latina: giro liberal-conservador y contestación normativa”, en Manuela Mesa (coord.), Ascenso del nacionalismo y el autoritarismo en el sistema internacional. Anuario 2018-2019, Madrid, Centro de Educación e Investigación para la Paz, 2019, pp. 107-126.

SAntino, Renato, "Embaixador dos EUA diz que Brasil 'terá consequências' se permitir Huawei no 5G", Olhar Digital, 30 de julio de 2020, https://olhardigital.com.br/noticia/embaixador-dos -eua-diz-que-brasil-tera-consequencias-se-permitir-huawei-no$5 \mathrm{~g} / 104348$

Schenoni, Luis, "Bipolarity or Hegemony? Latin America's Dilemma for the 21st Century". E-International Relations, 24 de febrero de 2019, https:/ / www.e-ir.info/pdf/77803

Silva, Consuelo, Ariel Noyola y Julian Kan (coords.), América Latina: una integración regional fragmentada y sin rumbo, Buenos Aires, Clacso, 2019.

Stewart, Patrick, "When the System Fails. COVID-19 and the Costs of Global Dysfunction”, Foreign Affairs, vol. 99, núm. 4, 2020, pp. 40-50.

Telias, Diego y Francisco Urdínez, "China’s Foreign Aid Determinants: Lessons from a Novel Dataset of the Mask Diplomacy During the COVID-19 Pandemic", borrador, agosto de 2020, https:/ /www.researchgate.net/publication/344035590 _China's_Foreign_Aid_Determinants_Lessons_from_a_Novel_ Dataset_of_the_Mask_Diplomacy_During_the_COVID-19_ Pandemic

Thwaites Rey, Mabel Cristina, "Alternativas contrahegemónicas desde el Sur global”, Grupos de trabajo seleccionados para el periodo 2016-2019, Clacso, https://www.clacso.org.ar/grupos_trabajo/detalle_gt.php?ficha $=1159 \& s=5 \&$ \&idioma=\#: :text $=\mathrm{En} \% 20 \mathrm{ese} \% 20$ sur $\% 20$ global $\% 20$ incluimos, degradaci $\%$ C3\%B3n\%20econ \% C3\% B3mica \% 2C\% 20pol\% C3\%ADtica $\% 20 y \% 20$ social

Turzi, Mariano, “The Age of Pressure Politics?”, Global Policy, 6 de agosto de 2020, https:/ /www.globalpolicyjournal.com/blog/ 06/08/2020/age-pressure-politics 
Turzi, Mariano, "Relaciones América Latina-Estados Unidos", en Thomas Legler, Arturo Santa Cruz y Laura Zamudio González (eds.), Introducción a las Relaciones Internacionales: América Latina y la Política Global, México, Oxford University Press, 2013, pp. 184-194.

Urdinez, Francisco, et al., "Chinese Economic Statecraft and US Hegemony in Latin America", Latin American Politics and Society, vol. 58, núm. 4, 2016, pp. 3-30.

VARAs, Gabriela, "China acusa a EE.uU. de 'crear caos' en Asia para mantener su hegemonía”, Emol, 24 de noviembre de 2020, https://www.emol.com/noticias/Internacional/2020/11/ 24/1004711/China-Estados-Unidos-caos-Asia.html

Vargas Hernández, José, "Perspectivas del institucionalismo y neoinstitucionalismo", Ciencia Administrativa, núm. 1, 2008, pp. 47-58.

WaLtz, Kenneth, Theory of International Politics, Nueva York, McGraw Hill, 1979.

White, Hugh, "China's One Belt, One Road to Challenge US-Led Order", The Straits Times, 25 de abril de 2017, https://www. straitstimes.com/opinion/chinas-one-belt-one-road-to-chal lenge-us-led-order

"West Feels Challenged by China's New 'Wolf Warrior' Diplomacy”, Global Times, 16 de abril de 2020, https://www.globaltimes. $\mathrm{cn} /$ content/1185776.shtml

XIng, Li y Abdulkadir Osman Farah (eds.), China-Africa Relations in an Era of Great Transformations, Surrey, Ashgate, 2013.

XING, Li, "China's Global Rise and Neoimperialism: Attitudes and Actualities”, en Immanuel Ness y Zak Cope (eds.), Palgrave Encyclopedia of Imperialism E anti-imperialism, Londres, Palgrave Macmillan, 2016.

XING, Li, "The Rise of China and its Impact on World Economic Stratification and Re-stratification", Cambridge Review of International Affairs, versión en línea, 2020, https:/ / doi.org/10.1080/ 09557571.2020.1800589

XING, Li, "The Rise of China and the US-Led World Order: Can Two Tigers Share the Same Mountain?”, en Bart Gaens y Ville Sinkkonen (eds.), Great-Power Competition and The Rising 
FI LXI-2 Covid-19, TENSIONES SINO-ESTADOUNIDENSES Y AL

US-China Rivalry, Helsinki, Finnish Institute of International Affairs, 2020, pp. 57-71.

Zakaria, Fareed, "The New China Scare. Why America Shouldn't Panic about its Latest Challenger”, Foreign Affairs, vol. 99, núm. 1, 2019, pp. 52-69. 
